\title{
Wladimir Vogels Flucht
}

Materialien zu einem kreativen Missverständnis

Wladimir Vogels Flucht ist bis heute die umfangreichste Auseinandersetzung mit Robert Walser. Ihre Uraufführung 1966 hätte ein Höhepunkt in Vogels Schaffen werden und die Feierlichkeiten zu seinem 70. Geburtstag krönen sollen. Es wurde schließlich zum wohl größten Misserfolg seines Lebens. Flucht ist die erste national und international rezipierte und gut dokumentierte Walser-Vertonung. Das Werk steht für die ambivalente Rezeptionsgeschichte in den 196oer-Jahren, als Robert Walser seinen festen Platz in der deutschen Literaturgeschichte noch nicht gefunden hatte. Das folgende Kapitel stellt diese Geschichte unter Einbezug neuer Quellen dar.

\subsection{Einleitung}

Flucht ist ein abendfüllendes musikalisch-literarisches Oratorium über das Leben von Robert Walser. Dramma-Oratorio nannte Vogel die von ihm entwickelte Gattung, bei der Sprech- und Singstimmen sowie Sprechchor und Orchester dicht und variationsreich ineinandergreifen. Die Besetzung von Flucht umfasst vier Sprech- und vier Singstimmen, Sprechchor und Orchester. Die Solo-Rollen sind definiert: Als Sprechstimmen (Schauspieler) werden eine jugendlich-helle Frauenstimme, eine tiefe Frauenstimme, eine jugendlich-helle Männerstimme sowie eine tiefe Männerstimme verlangt, an Singstimmen ein lyrischer Sopran, ein Alt, ein lyrischer Tenor sowie ein BassBariton. Die Bearbeiter des Textbuchs nach Texten von Robert Walser und Christian Morgenstern sind Wladimir Vogel selbst sowie Paul Müller.

Zentrales Element von Vogels Oratorien ist der Sprechchor. Eigens zur Aufführung der Werke von Wladimir Vogel gründete Ellen Widmann, die Enkelin des frühen Walser-Förderers Josef Viktor Widmann, 1951 den Kammersprechchor Zürich. Bei der Uraufführung von Flucht am 8. November 1966 in der Tonhalle Zürich sprach Ellen Widmann die Hauptpartie. Vogel standen die großen Charakterdarstellerinnen und -darsteller des Schauspielhauses, ein ausgezeichnetes Solistenensemble und der präzise Kammersprechchor Zürich unter der Gesamtleitung des in neuer Musik erfahrenen Dirigenten Francis Travis zur Verfügung. Trotz diesen guten Voraussetzungen wurde das 
in Zwölftontechnik komponierte Walser-Oratorium bis heute nur ein einziges Mal aufgeführt und nur einmal vollständig im Schweizer Radio ausgestrahlt.

\subsection{Die Flucht der Schüler}

Am 9. November 1966, einen Tag nach der Uraufführung, schreibt der Komponist Jacques Wildberger seinem ehemaligen Kompositionslehrer Waldimir Vogel einen Brief, in dem er sich dafür entschuldigt, dass er leider die Vorstellung habe vorzeitig verlassen müssen, um den Zug nach Basel zu erwischen. Er witzelt:

Der Titel Ihres Werkes haftet jetzt als ein Odium an uns, und doch sind wir ganz unschuldig. Wie gerne wären wir noch geblieben, hätten wir wenigstens kurz teilgenommen an der Begrüssung aller Beteiligten, was doch unbedingt zu einem solchen Anlass gehört, wie gerne hätten wir Ihnen gleich an Ort und Stelle gratuliert. Nun müssen wir das nachholen, leider ohne Ihnen zugleich die Hand zu drücken ...1

Und das war sie auch schon, die Gratulation! Zum Werk und zur Aufführung verliert Wildberger kein Wort. Sein Kollege und Freund Robert Suter - ebenfalls ehemaliger Schüler von Vogel - entschuldigt sich zwei Tage später bei seinem Lehrer für den vorzeitigen Aufbruch, schimpft über die »erbärmliche Angelegenheit« des Zugfahrplans und kalauert weiter: »Es war also gewissermassen eine Flucht aus der Flucht, wenn ich mir dieses kleine Wortspiel erlauben darf.« Und auch er gratuliert lakonisch zum »für Sie bestimmt sehr typischen Werk «.2

Man kann aus den Briefen von Vogels Basler Schülern und Freunden förmlich herausspüren, wie sie während der Rückfahrt über das Werk hergezogen sind und sicher froh waren, dass sie ihrem Lehrer weder die Hand drücken noch etwas halbwegs Freundliches zum Stück sagen mussten. ${ }^{3}$ Und à propos

1 Wildberger: Brief vom 9. November 1966. Ich danke Heinrich Aerni, dem Betreuer des Nachlasses Vogel in der Musikabteilung der Zentralbibliothek Zürich, für die große fachliche Unterstützung bei meinen Recherchen.

2 Suter: Brief vom 11. November 1966. Auch die Baslerin Aja Petzold kalauert mit dem Titel des Werkes, dessen Aufführung sie frühzeitig habe verlassen müssen: »Es tat uns sehr leid, Dein großes Konzert so schnell und ohne ein Wort sagen zu können, verlassen zu müssen. Es hätte den Anschein erwecken können, als hätten wir die >Flucht< ergriffen.« (Petzold: Brief vom 12. November 1966)

3 Zum Verhältnis Vogels zu seinen Schülern vgl. Brotbeck: Das »kleine Hänschen« Hermann Meier und seine Mitschüler. 
>erbärmliche Angelegenheit< des Zugfahrplans: Die Schlaumeier hätten sehr wohl bis zum Ende der über zweieinhalbstündigen Aufführung bleiben und den letzten Schnellzug um 23:13 Uhr ab Zürich nehmen können. ${ }^{4}$

Auch von der Kritik wurde Flucht ambivalent bis kritisch aufgenommen. Selbst wohlwollende Kritiken verhielten sich neutral und beschränkten sich in der Berichterstattung auf Vogels Ausführungen zur Idee des Dramma-Oratorios.

Das ist insofern erstaunlich, als der am Schalttag 1896 geborene Vogel nur wenige Monate früher, anlässlich seines 70. Geburtstags am 1. März 1966, in allen deutschen und schweizerischen Feuilletons gefeiert wurde: Man lobte ihn als Komponisten, der zwischen Skrjabin und Schönberg, quasi zwischen Ost und West, die Synthese gefunden habe und eine wichtige Rolle als Vermittler zwischen den Generationen spiele. Eine Jahrzehnte dauernde Isolation schien endlich überwunden und die Feststellung von Friedrich Geiger, dass »Vogels Position ab den 6oer-Jahren als weitestgehend isoliert zu bezeichnen « 5 sei, trifft mindestens für das Jahr 1966 keineswegs zu. Wladimir Vogel wurde neben die Großen seiner Zeit gestellt und als Klassiker der Moderne gefeiert, insbesondere als Erfinder des Sprechchors und des Dramma-Oratorios, dessen Konzept in den Kontext von Brechts epischem Theater gestellt wurde. Die seriellen Schulen zeigten 1966 deutliche Anzeichen der Erschöpfung, und Vogels gemäßigte und auf Hörbarkeit und Verständlichkeit angelegte Verwendung der Zwölftontechnik wurde als wichtiger Mittelweg anerkannt. Im gleichen Jahr stellte der Basler Musikwissenschaftler Hans Oesch die erste große Gesamtschau zu Vogel fertig. ${ }^{6}$ Sie beruht auf zahlreichen Gesprächen mit dem Komponisten und prägt im Wesentlichen bis heute die Sicht auf ihn.

\subsection{Verkleidung als Skrjabinist}

Eigentlich beschreibt Oesch den Komponisten 1966 so, wie Vogel sich am liebsten in der Musikgeschichte gesehen hätte. Es gelang Vogel sogar, Oesch seine radikalen kommunistischen Positionen der 1920er-Jahre zu verschweigen. Erst der Musikwissenschaftler Walter Labhart entdeckte 1978 die Schallplatte mit Vogels Heimlichem Aufmarsch, auf der sich auch Eislers Vorwärts und nicht vergessen befindet, stieß am 2. Februar 1979 in der Musikabteilung

4 Ich danke David Kunz von der Stiftung Historisches Erbe der SBB Windisch für die entsprechende Fahrplanauskunft.

5 Geiger: Die Dramma-Oratorien von Wladimir Vogel, S. 66. Friedrich Geiger hat in seiner umfassenden Studie Flucht großformal und im Detail analysiert und alle verwendeten Walser-Stellen identifiziert.

6 Vgl. Oesch: Waldimir Vogel. 
der Deutschen Staatsbibliothek in Ost-Berlin auf die kommunistischen Werke Vogels ${ }^{7}$ und führte in seiner eigenen Schrift zum Komponisten erstmals dessen Agitprop-Gesänge im Kompositionsverzeichnis auf. ${ }^{8}$ Aufgrund der Forschungen von Friedrich Geiger und Carlo Piccardi ${ }^{9}$ wissen wir heute, wie sehr Vogel in der Berliner Zeit ab 1926 den gezielten Charmeoffensiven der sowjetischen Propagandamaschinerie gegenüber Exilrussen erlegen war. Er setzte sich als Organisator, Musikkritiker und Komponist für die kommunistische Bewegung und die Förderung sowjetisch-deutscher Kontakte ein. Seine Agitprop-Gesänge erschienen deutsch und russisch und wurden in Auflagen von mehreren tausend Exemplaren gedruckt. Mit großer Wahrscheinlichkeit wird er im Kreis der Arbeitermusikbewegung im Übrigen auch James Simon begegnet sein.

Weshalb Vogel diese Zeit aus seiner Biografie auszuradieren versuchte, muss noch im Detail untersucht werden. Sicherlich spielte die Enttäuschung über das stalinistische Regime, dessen Grausamkeit und Willkür viele kommunistisch orientierte Antifaschisten unterschätzt hatten, eine wichtige Rolle. Auch das gesellschaftliche und politische Klima der damaligen Schweiz wird ein Umstand gewesen sein, der es dem langjährigen Exilanten Vogel ratsam erscheinen ließ, sein frühes politisches Engagement zu vertuschen. Nach Hitlers Machtübernahme 1933 verließ Vogel auch seiner jüdischen Herkunft ${ }^{10}$ wegen Berlin und emigrierte in die Schweiz, wo er die Schriftstellerin und Psychoanalytikerin Aline Valangin kennenlernte und mit ihr - unterbrochen von Aufenthalten in Brüssel, London und Paris - in Comologno in der berühmten Villa La Barca lebte. Ab 1939 blieb er definitiv im Tessin. Von der Welt abgeschnitten, komponierte er eines der wenigen antifaschistischen

Telefonische Auskunft von Walter Labhart am 29. Februar 2016 (120. Geburtstag von Vogel) und undatierter Brief von Mitte April 2016 an den Autor.

8 Vgl. Labhart: Wladimir Vogel. Als Herausgeber von Vogels Schriften hat Walter Labhart schon 1977 aufgrund bibliografischer Recherchen erstmals den Agitprop-Gesang Der heimliche Aufmarsch gegen die Sowjetunion erwähnt.

$9 \quad$ Vgl. Piccardi: Le sotterranee convergenze politiche di Wladimir Vogel.

10 Auch seine jüdische Herkunft hat Vogel in der Schweiz aus naheliegenden Gründen verschwiegen. Sein ebenfalls jüdischer Schüler Rolf Liebermann spricht den schweizerischen Antisemitismus offen an, zum Beispiel bei einem Kommentar zur Jury des Schweizerischen Tonkünstlervereins: »Von den Aufgeführten sind mir persönlich nur zwei bekannt: Mieg, der P.Mg der >Weltwoche`, ein Intimus des Sacher-Kreises und Aeschbacher, der Papa der fruchtbaren Aeschbacher-Dynastie, der vor bald 20 Jahren mein Gesangslehrer in der Kantonsschule war [...]. Ich habe ihm nie vergessen, dass er mich als 15 oder 16 Jährigen mal mit einer antisemitischen Bemerkung geohrfeigt hat. (Ein komisches Wiedersehen!)«. Liebermann: Brief vom 10.08.1943. 
Werke, die während des Zweiten Weltkriegs in der Schweiz entstanden sind, nämlich die beiden Teile des Thyl Claes nach Charles de Costers Ulenspiegel.

Während des Krieges musste Vogel seine Aufenthaltsbewilligung jährlich erneuern lassen. Das Auffliegen seiner kommunistischen Vergangenheit und die Tatsache, dass seine Werke in Moskau ediert worden waren, hätten die Chancen auf Verlängerung sicher gemindert. Und auch nach dem Krieg wäre es der Karriere nicht förderlich gewesen. ${ }^{11}$ Vogel erhielt erst 1954 das Schweizer Bürgerrecht.

1966 allerdings hätte Vogel seine Beziehung zum kommunistischen Musikerkreis in Berlin mindestens andeuten können, ohne gleich in Misskredit zu fallen. Er tat etwas anderes: Er muss seinem Biografen Hans Oesch ein erstes Kapitel mit dem Titel »Skrjabin« suggeriert haben. Darin beschreibt Oesch die persönliche Begegnung Vogels mit dem russischen Komponisten und Pianisten Skrjabin auf eine Weise, die nahelegt, dass Vogel Unterricht bei Skrjabin genossen hatte.

In Wirklichkeit hatte Vogel als Teenager einmal die Gelegenheit, Skrjabin nach einem Konzert zu begrüßen,; ${ }^{12}$ beim Ausbruch des Ersten Weltkriegs wurde der 18-jährige Vogel, der damals noch in Moskau lebte, als Sohn eines Deutschen und einer Russin ins 1200 km Luftlinie entfernte Birsk verbannt. 1915 starb Aleksandr Skrjabin. Von einer intensiven Beziehung kann also keine Rede sein, und in Vogels Schriften spielt der Name Skrjabin bis Ende der 196oer-Jahre eine untergeordnete Rolle, wird er doch nur im Zusammenhang mit anderen großen Klavierkomponisten genannt. Erst als Vogel durch Oeschs Publikation erfolgreich als Bindeglied von Ost und West etabliert wurde, begann er sich - auf Einladung von Redaktionen - in verschiedenen Texten zu Skrjabin zu äußern. Diese Kommunikationsstrategie war sehr erfolgreich;

11 Es sei erinnert an die Hetze gegen Hermann Scherchen, einen der wichtigsten Dirigenten, der in der Schweiz je gewirkt hat. Seit 1922 dirigierte er das Stadtorchester Winterthur. Als er 1944 Chefdirigent des Studio-Orchesters Beromünster wurde, gelangte der Vorstand des Schweizerischen Tonkünstlervereins an den Bundesrat mit der Bitte, die Wahl von Scherchen, »der zu dem schweizerischen Wesen fremd ist«, rückgängig zu machen. Scherchen wurde $195^{\circ}$ in Winterthur und beim Radioorchester entlassen, weil er in Prag für die kommunistische Bewegung eingetreten war. Vgl. Brotbeck: Dauer und Verdrängung. Wie unerbittlich die Schweiz gegen Kommunisten vorging, hatte Vogel allerdings auch beim ersten Ehemann von Aline Valangin erlebt, dem Rechtsanwalt Wladimir Rosenbaum, dem das Anwaltspatent entzogen wurde. Vgl. Kamber: Geschichte zweier Leben.

Wahrscheinlich war es nicht mehr als ein Händedruck, dessen Überbewertung auch auf Oesch zurückgeht. Bezeichnenderweise erwähnt Vogel die persönliche Begegnung mit Skrjabin in einem langen Brief vom 19. März 1984 an Bálint András Varga in Budapest, der nach Vogels russischer Vergangenheit fragte, mit keinem Wort und schreibt nur von Konzerten mit Skrjabin, die er besucht habe (vgl. Vogel: Brief vom 19.03.1984). 
sie passte zu den extremen Ost-West-Spannungen der damaligen Zeit. Die Konstruktion, Vogel habe quasi zwischen Skrjabin und Schönberg vermittelt, wurde von den meisten Vogel-Forscherinnen und -Forschern übernommen. ${ }^{13}$

\subsection{Opus Magnum als Projekt zum 70. Geburtstag}

Das Walser-Oratorium und dessen Uraufführung waren von Vogel als Höhepunkt des Jubiläumsjahrs geplant worden. Mit seinem Wechsel zum Bärenreiter-Verlag erhoffte er sich den Durchbruch in Deutschland. Er wollte sich zudem im Musikleben Zürichs, wohin er 1965 umgesiedelt war, fest verankern und den Ruhm des von ihm stark mitgeprägten Zürcher Kammersprechchors noch vermehren.

Flucht sollte Vogels Bedeutung und Rolle in der Musikgeschichte des 20. Jahrhunderts festschreiben. Mit dem Dramma-Oratorio hatte Vogel eine neue Form des Musiktheaters geschaffen, bei der Musik und Sprache autonome Schichten bleiben. Meist kombiniert Vogel in diesem Genre Sprech- und Singstimmen; der rhythmisch polyphon gesetzte Sprechchor bildet das Verbindungsglied zwischen Musik und Sprache. Unter all seinen Dramma-Oratorios sucht er bei Flucht die artifiziellsten, technisch anspruchsvollsten Überlagerungen der verschiedenen Materialebenen. Das zweite, was Vogel in die Waagschale der Musikgeschichte werfen wollte, war seine spezifische Ausprägung der Zwölftontechnik, bei der die Reihenstruktur melodisch und harmonisch nachvollziehbar und hörbar ist. In Flucht strukturiert er das Werk auch großformal mit den Mitteln der Dodekaphonie, indem er für jeden Abschnitt eine andere Permutationsform der symmetrischen Allintervallreihe verwendet.

Im Vorfeld der Uraufführung unternahm Vogel sehr viel, um auf die Bedeutung des Werks hinzuweisen. Er verschickte an seinen großen Freundeskreis Kopien einer Dokumentation zur Entstehungsgeschichte, die seine Frau zusammengestellt hatte. ${ }^{14}$ Er schrieb dem Schriftsteller Martin Walser, um ihn

13 Vgl. Levitz: Teaching New Classicality. Friedrich Geiger relativiert nachdrücklich die Bedeutung der persönlichen Begegnungen mit Skrjabin, hält aber trotzdem an der lebenslangen Relevanz von Skrjabin für Vogel fest. Auch Doris Lanz, die Vogels Verankerung in der Neuen Sachlichkeit und die Beziehung zu Hanns Eisler genau nachzeichnet, basiert ihre Studie noch 2009 auf der »Synthese von Ost und West« (Lanz: Zwölftontechnik mit doppeltem Boden, S. 109-125), der Vogel mit seinem Komponieren zugestrebt habe. Wie sehr Vogel bis zum Schluss an der einfachen Ost-West-Konstruktion festhielt, erlebte ich in Gesprächen mit dem betagten Komponisten ab 1982 selber: Er bestand immer darauf, Skrjabin und Schönberg in seinem Werk vereinigt zu haben, und verkürzte dies auf den Gegensatz von Vertikale (Skrjabin) und Horizontale (Schönberg).

Vgl. Vogel: »Die Flucht«. Tagebuch einer Komposition. 
auf sein Projekt aufmerksam zu machen, denn auch »Prof. Hans Mayer wie Th. W. Adorno waren von meinem Vorhaben sehr begeistert «..$^{15} \mathrm{Er}$ sprach einen langen Kommentar im Radio ${ }^{16}$ und gab eine Woche vor der Uraufführung einen Einführungsvortrag in der Tonhalle Zürich, an dem als Co-Referent Paul Nizon ${ }^{17}$ eingeladen war, der Walser in den Kontext von Hölderlin und Kafka stellte. In den großen Zürcher Tageszeitungen folgten Besprechungen dieser Einführungsveranstaltung. ${ }^{18}$

Vogel stellte in diesen Einführungen Flucht als Schnittpunkt von zwei Entwicklungen dar: Einerseits bildet das Walser-Oratorium den letzten Teil einer Trias von großangelegten, abendfüllenden Dramma-Oratorios, die sein kompositorisches Schaffen umspannen; beginnend mit Wagadus Untergang durch die Eitelkeit (VWV 122) (1930) und weitergeführt mit den beiden Teilen von Thyl Claes (VWV 100) (1938/1945). Andererseits folgt Flucht einer jüngeren Entwicklung Vogels, nämlich seiner Beschäftigung mit Biografien realer und gleichzeitig unterschätzter Künstlerfiguren, die $195^{8}$ mit Giovanni Battista Pergolesi ${ }^{19}$ einsetzt, 196o auf den Maler Amedeo Modigliani ${ }^{20}$ erweitert wird und 1962 bis 1964 mit dem Dichter Robert Walser endet. Dass alle drei Werke in ihrer starken Gewichtung des Erotischen auch autobiografische Spiegelungen enthalten, ist gerade in diesem Lebensabschnitt Vogels naheliegend, da er sich von seiner langjährigen Lebenspartnerin und zweiten Frau Aline Valangin trennte.

Bei der Berliner Aufführung von Wagadus Untergang durch die Eitelkeit 1957 mit dem St. Galler Kammerchor unter der Leitung von Werner Heim ${ }^{21}$ saß neben Wladimir Vogel eine Gönnerin des Chors, die früh verwitwete Idmarie Knobel-Tschudi aus Herisau. Sie hatte in Ascona, wo Vogel seit zwei Jahrzehnten mit Aline Valangin zusammenlebte, ein Ferienhaus. Aus den

\footnotetext{
15 Vogel: Brief vom 25.10.1965.

16 Vgl. Vogel: Einführungsvortrag zum Dramma-Oratorio $»$ Flucht«.

17 Die erste Anfrage für das Ko-Referat ging an Werner Weber (vgl. Vogel: Brief vom 10.08.1966). Vermutlich sagte Weber ab, um als Feuilletonchef der Neuen Zürcher Zeitung in der Auseinandersetzung mit Jochen Greven nicht Partei ergreifen zu müssen (vgl. Kap. 3.9).

18 Vgl. Reich: Einführung in die »Flucht« (Neue Zürcher Zeitung); Gerteis: Vor der Uraufführung des neuen dramma-oratorio »Flucht« von Wladimir Vogel (Tages-Anzeiger).

19 Vogel: Alla Memoria di Giovanni Battista Pergolesi.

20 Vogel: Meditazione sulla maschera di Modigliani.

21 Die deutsche Erstaufführung von Wagadu am 1. Oktober 1957 bildete Vogels Durchbruch in Deutschland. An den Berliner Festwochen wurde Vogels frühes Oratorium neben Werken der damals international führenden Komponisten Blacher, Boulez, Britten, Hindemith und Nono aufgeführt. »Die Aufführung [...] läßt sich an Glanz und Authentizität schwer übertreffen. Sie trug zum großen Erfolg bei, den auch der Komponist immer wieder quittieren durfte.« (Stuckenschmidt: Musik bei den Berliner Festwochen II)
} 
regelmäßigen Begegnungen entstand eine Liebesbeziehung, die 1962 zu Vogels Umsiedlung nach Herisau führte. 1966 wurde die 27 Jahre jüngere Idmarie Knobel-Tschudi Vogels dritte Frau. Diese private Angelegenheit gab viel zu reden; insbesondere die ehemaligen Schüler hielten zu Aline Valangin, weil sie nicht verstanden, weshalb Vogel eine so faszinierend autonome Frau verlassen konnte. $^{22}$

Flucht ist auch ein Resultat dieser neuen Liebe, denn Idmarie Vogel war am Oratorium beteiligt. Wegen ihr ist Vogel in Herisau überhaupt erst auf den ihm zuvor völlig unbekannten Robert Walser gestoßen. Das erwähnte Tagebuch einer Komposition setzt sich aus langen Briefen zusammen, in denen Vogel seiner Freundin den Fortgang seiner Komposition schildert und aus denen Idmarie Vogel den maschinengeschriebenen Bericht zur Entstehung des Werks exzerpierte. ${ }^{23}$ So sind wir über die Entstehung kaum eines anderen Werks von Vogel so genau unterrichtet. Wahrscheinlich ist auch der starke Einfluss von C. G. Jung, auf den erstmals Friedrich Geiger ${ }^{24}$ aufmerksam machte, auf Idmarie Vogel zurückzuführen, denn sie besuchte C. G. Jungs Vorträge in Zürich und wurde durch seine Theorien stark beeinflusst. ${ }^{25}$ Obwohl Vogels zweite Frau, Aline Valangin, sogar eine ausgebildete Analytikerin im Jung'schen System war, finden sich in seinem früheren Werk wenig Spuren von Jungs Psychologie.

\subsection{Das Libretto von Paul Müller}

Initialzündung für das Werk war die Kleine Auslese, die der junge Herisauer Germanist und Redaktor bei der Appenzeller Zeitung Paul Müller 1962 mit Schriften von Robert Walser herausgegeben hatte. Vogel stieß zufällig auf diese Publikation. Müller hatte während seiner Jugendzeit in Herisau den berühmten

22 Die Verehrung für Aline Valangin und die Distanz zu Vogels letzter Frau wurden mir in verschiedenen Gesprächen mit dem Vogel-Schüler Jacques Wildberger deutlich vermittelt. Der ausführliche Briefwechsel zwischen Vogel und Valangin in der Zentralbibliothek Zürich zeugt allerdings auch von einer konfliktreichen, gewissermaßen >modernen< Beziehung zwischen zwei emanzipierten und selbstständigen Künstlerpersönlichkeiten, die sich immer wieder zusammengefunden haben. 1966 erreichte das Zerwürfnis zwischen Vogel und Valangin seinen Höhepunkt und führte zum weitgehenden Abbruch des Kontakts bis kurz vor Vogels Tod. Vogel warf seiner früheren Frau vor, gegen ihn bei gemeinsamen Freunden intrigiert zu haben.

23 Vgl. Geiger: Die Dramma-Oratorien von Wladimir Vogel, S. 164. Diese Briefe an Idmarie Vogel sind heute verschollen.

24 Vgl. ebd., S. 174-177.

25 Für diese und andere Informationen aus dem privaten Umfeld danke ich Beatrice Knobel, Idmarie Vogels Tochter aus erster Ehe; Telefongespräch vom 07.02.2016. 
Wanderer unter den Patienten der Herisauer Klinik oft gesehen; er setzte sich eine Zeit lang stark für Robert Walser ein. Die Kleine Auslese erschien in Zusammenhang mit dem von Lorenz Balmer geschaffenen Walser-Brunnen in Herisau, an dessen Enthüllung am 16. Juni 1962 der Alt-Präsident der Bundesrepublik Deutschland Theodor Heuss und Alt-Bundesrat Philipp Etter teilnahmen. Sehr geschickt war es Paul Müller gelungen, für die Finanzierung und die Einweihungsfeierlichkeiten des Denkmals alle wichtigen Lebensstationen Walsers zu vernetzen: die Städte Biel, Bern und Herisau, aber eben auch Deutschland. Die Einladung zur Einweihung wurde dem Büchlein beigelegt mit dem Vermerk: »Das Büchlein wird u. a. den Gymnasien und Seminarien als Klassenlektüre geschenkt «. ${ }^{26}$ Eine wichtige Stütze dieser Bemühungen war Carl Seelig, dessen Ausgabe mit späten Walser-Gedichten Paul Müller schon 1958 ausführlich rezensiert hatte. ${ }^{27}$ Seelig starb am 15 . Februar 1962 bei einem Unfall und konnte die Einweihung des Walser-Brunnens nicht mehr erleben, hatte aber zuvor schon die Erlaubnis zur Publikation der Kleinen Auslese erteilt. Ein wichtiger Teil der Texte, die Müller später in der Flucht verwendete, findet sich schon in dieser frühen Sammlung, vor allem auch ein längerer Ausschnitt aus dem Roman Jakob von Gunten, der in Vogels Oratorium den größten Teil des Werks ausmacht.

Eingefügt in das knapp 8o Seiten umfassende Büchlein sind stichwortartige biografische Notizen zu den Gebrüdern Karl und Robert Walser von Paul Müller und ein Text über Robert Walser von Christian Morgenstern. Auch dieser Morgenstern-Text wurde später ins Libretto eingearbeitet. Er zeigt, wie sehr man 1962 die Bedeutung und Validität von Robert Walser als Autor noch mit einem berühmten Zeitzeugen untermauern musste, denn damals war man sich über die Qualität von Walsers Texten, soweit man sie überhaupt kannte, keineswegs einig. Der frühe Morgenstern-Text, der sich auf die Berliner Zeit von Walser bezieht, verrät aber auch, in welcher Perspektive Müller Robert Walsers Schaffen betrachtete: glanzvoller Aufbruch und große Erwartungen an den Dichter in Berlin, dann die schmachvolle Rückkehr in die Schweiz und die Erstarrung in der Kleinprosa, schließlich der Zerfall in Herisau. Christian Morgenstern beschreibt die Berliner Aufbruchszeit in blumigen Worten:

Dieser Mann wird sein ganzes Leben lang so weiterreden und er wird immer schöner und schöner und immer bedeutender und bedeutender reden; seine Bücher werden ein eigentümlicher und wundervoller Spiegel des Lebens werden, des Lebens, das er, heute mehr fast eine Pflanze noch als ein Mensch, durchwächst und durchwachsen wird. [...] Jetzt gibt er es noch wie ein Kind:

26 [o. A.]: Einladungskarte zur Einweihung der Walser-Gedenkstätte in Herisau, im Besitz des Autors.

27 Vgl. Müller: Auf der Suche nach dem Ursprung (Stuttgarter Zeitung). 
die Nichtachtung dessen, was ich das Bürgerliche im Menschen nenne, und das Sehen der Welt als eines immerwährenden Wunders; gereift wird er dieses, wie man meinen sollte, sich von selbst verstehen müssende Durchgreifen zum Wesentlichen, zu seiner bewußten Aufgabe machen und einer der stärksten Verlocker zur Freiheit werden, [...]. Ob er auch solch einen Gedanken, solch ein neues Wort (wie es Dostojewsky nennt) finden wird, steht dahin - aber wer weiß, ob in diesem wunderlichen Sinnierer nicht Cromwells Wort wieder einmal wahr werden wird: »Der kommt oft am weitesten, der nicht weiß, wohin er geht. « ${ }^{28}$

In einem langen Aufsatz, den Paul Müller am Wochenende der WalserdenkmalEnthüllung in der Neuen Zürcher Zeitung publizieren konnte, wird die Dreiteilung von Walsers Leben schon im Titel thematisiert: >Aufbruch< in Berlin, >Einfahrt< in Biel, >Zerfall< in Bern. ${ }^{29}$ Schon bald erwies sich diese Sicht auf Walsers Berner Zeit als überholt, weil der Dichter gerade in Bern eine enorme literarische Aktivität entfaltete. Trotzdem bleibt der Aufsatz, dessen Sprachstil sich an Werner Webers literaturkritischem Duktus orientiert, eine beachtliche sprachliche und intellektuelle Leistung des jungen Germanisten und ein wichtiges Zeugnis der frühen Walser-Rezeption. Später wandte Müller sich dem politischen Journalismus zu; ${ }^{30}$ sein Vorhaben, bei Emil Staiger über Walser zu promovieren, kam nicht zustande. Seine letzte öffentliche Beschäftigung mit Walser ist ein Radiofeature, das zu großen Teilen auf einer ersten Fassung des Librettos für Vogels Flucht basiert. Müller spricht am Mikrofon den biografischliterarischen Kommentar, der junge Wolfgang Reichmann gestaltet Walsers Texte und trifft auf grandiose Weise den wechselvollen Klang seiner Sprache. Unter dem Titel Ich wanderte und wandere noch. Das Leben Robert Walsers in Selbstzeugnissen und Texten wurde das Feature am 27. Dezember 1963 von Radio Beromünster ausgestrahlt,, ${ }^{31}$ ergänzt mit einem Kommentar von Martin Walser. $^{32}$

Dieser 40 Minuten dauernde Radiobeitrag lässt erahnen, was Müller ursprünglich in seinem Libretto zu Flucht hätte realisieren wollen, nämlich einen an Walsers Sprache angelehnten Kommentar, der die Originaltexte

28 Zit. nach Walser: Kleine Auslese, S. 66. Das Oliver Cromwell zugeschriebene Zitat nahm Morgenstern bereits als Motto für die 1891 begründete Zeitschrift Deutscher Geist. Es handelt sich beim Text zu Walser um eine Tagebuchnotiz aus dem Jahre 1907, die Morgenstern einem Gutachten über Walser beilegte, das er für Bruno Cassirer verfasste; vgl. Geiger: Die Dramma-Oratorien von Wladimir Vogel, S. 167.

29 Vgl. Müller: Aufbruch, Einfahrt, Zerfall.

$30 \quad$ Müller starb 1997 mit 66 Jahren; vgl. [o. A.]: Nachruf auf Paul Müller.

31 Vgl. Müller: Ich wanderte und wandere noch; dieser Beitrag zählt nach einem sehr frühen Dokument von Hans Bänninger zu Der Gehülfe (1936) zu den ersten erhaltenen Beiträgen zu Walser im Schweizer Radio.

32 Vgl. Walser: Dr. Martin Walser spricht über den Dichter Robert Walser. 
vorbereitet und einbettet. Walsers Sprache und die Sprache des Kommentars sollten dabei eng ineinandergreifen.

\subsection{Wladimir Vogels Bearbeitung des Librettos}

Wladimir Vogel lehnte diese Libretto-Konzeption jedoch ab. Die im Nachlass erhaltenen Dokumente zeigen, wie Vogel Müllers ursprüngliches Libretto zerstückelte und die Schnipsel neu collagierte. Der Komponist strich vieles und akzeptierte nur ihm willkommene Teile.

Vogel interessierte sich vor allem für Walsers Biografie und misstraute dessen Sprachstil, der ihm >zeitgebunden< erschien.

Ich komponiere so mit Walsers eigenen Worten ein Stück über Robert Walser. So konnte ich die Abwicklung des Dramas ohne Rücksicht auf Robert Walsers Sprachstil, der ja zeitgebunden ist, auf die musikalische Ebene heben und ihm meine Musik unterlegen. So identifiziert sich meine Musik nicht mit seinem Sprachstil, wohl aber mit seiner dich[t]erischen Welt, [die,] wie jede große Kunst, nicht nur zeitgebunden, sondern als solche - zeitlos ist. ${ }^{33}$

Vogel gibt auch freimütig zu, in Walsers Texte redaktionell eingegriffen und das `fast Barocke< vereinfacht zu haben, um Monumentales setzen zu können:

Als Text verwende ich verschiedene Versionen, je nach Bedürfnis der musikalischen Form, ob ich viel oder wenig Text für das Stück brauche. Das »Literarische« spielt dabei eine nebensächliche Rolle, ebenso der Satzbau, etymologisch, unter Freilassung von Hilfsverben oder andern Wörtern, der Vereinfachung und Monumentalisierung der Sprache wegen. Diese ist bei Walser fast barock und verliert sich oft in Kleinigkeiten, wiederholt sich usw. ${ }^{34}$

Aus diesem Misstrauen gegen >fast barocke Wendungen < heraus lehnte Vogel auch den biografischen Teil von Müllers Libretto ab und strich fast alles, bis zum Schluss nur die kargen Lebensdaten übrigblieben, die Müller in die Kleine Auslese integriert hatte. So ähnelt der erste Teil in seiner Sachlichkeit einem Theaterprolog von Bertolt Brecht.

Bei der Vertonung dieses ersten Teils will und muss Vogel aus dem reduzierten Sprachmaterial allerdings doch Musik machen; deshalb belebt er

33 Vogel: »Die Flucht«. Tagebuch einer Komposition, S. 1. Das Tagebuch ist auch aufgenommen in Vogels Schriften und Aufzeichnungen über Musik, S. 33-53; dort ist diese Stelle zu Robert Walser bezeichnenderweise aber nicht abgedruckt.

34 Vogel: Schriften und Aufzeichnungen über Musik, S. 34. 
es. Der Sprechchor spielt mit den Jahreszahlen von Walsers Biografie; Vogel versucht sogar, neckisch zu sein, und lässt den Sprechchor bei der Erwähnung des Bund-Redaktors Josef Viktor Widmann, der Walser als erster publizierte, Beifall klatschen. So wird der Text, den Vogel radikal von >Barockem < befreit, nachträglich wieder ornamentiert. In einigen Kritiken wurde der befremdende Manierismus dieses Vorgehens beanstandet. ${ }^{35}$

Paul Müller wurde als Librettist übrigens zunehmend zurückgedrängt; in der Kommunikation der Uraufführung erschien er nur noch am Rande. Im Radiovortrag erwähnt ihn Vogel nur beiläufig wegen »biographischer Daten, die mir Paul Müller ausführlich mitteilte und mit Zitaten von Originaltexten erhärtete«. Diese habe er dann mit den anderen von ihm »ausgewählten Originaltexten verbinden $\aleph^{36}$ müssen.

Aber nicht einmal im biografischen Teil von Flucht wollte sich Vogel auf Walser wirklich einlassen. Ihn interessierte nämlich nicht der Einzelfall:

Ich stiess auf ein künstlerisches und menschliches Problem, das allerdings nicht nur Robert Walser selbst betraf, sondern auf Viele, wenn nicht auf alle Künstler bezogen werden könnte, und insbesondere auf Künstler unserer so zerrissenen Zeit. Der Entschluss, dieses Problem aus dem Einzelfall zum Allgemeinfall zu erheben und zum Thema einer Komposition zu machen, bekam deutlichere Umrisse. ${ }^{37}$

Diesen Allgemeinfall wollte Vogel auch psychologisch ergründen und erklären. Das führt zu einer ziemlich gewagten Interpretation bzw. Textzusammenstellung im ausgedehnten zweiten Teil, der weitgehend auf Walsers Roman Jakob von Gunten beruht. Vogel interpretiert diesen Teil im Sinne von Jungs dualer Sexualtheorie, also der damals in der Populärpsychologie weit verbreiteten Überzeugung, dass in jedem Geschlecht auch Anteile des anderen enthalten seien, Männer also eine Anima und Frauen einen Animus in sich trügen. Über drei Stufen weiblicher Emanationen, nämlich von Walsers kranker Mutter über eine Prostituierte bis schließlich zum >Fräulein< als weiblichem Idealbild, wird dargestellt, woran Robert Walser eigentlich erkrankt sei, nämlich an seiner Liebesunfähigkeit und daran, dass er seine Anima in sich ausgelöscht habe. Friedrich Geiger hat erstmals auf den Einfluss von Jungs Gedankenwelt auf Vogels Schaffen seit Jona ging doch nach Ninive (1957) hingewiesen und im Falle von Flucht diese psychoanalytische Sicht auf den Romanstoff umfassend dargelegt und folgendermaßen zusammengefasst:

35 Die Begriffe >Manier und >Manierismus< tauchen in vielen Kritiken auf; vgl. SeelmannEggebert: Tonhalle-Gesellschaft Zürich. Wladimir Vogel. Die Flucht; Schneider: Wladimir Vogels Walser-Oratorium; Oesch: Zürich. Musikalisches Porträt des Dichters Robert Walser.

37 Ebd., S. 1. 
Und es ergibt sich die conclusio, auf die Vogels Deutung hinausläuft: Walser mußte zwangsläufig als Dichter verstummen, nachdem er die »weiblichen« Impulse ausgeschaltet, der »Hinwendung zum Du«, dem Kontakt mit den Menschen entsagt hatte. ${ }^{38}$

Dieses moralisierende Fazit des Oratoriums wird schon im Motto des Werks gefasst (vgl. Abb. 4): Vogel setzt je einen von ihm Morgenstern und Walser zugeschriebenen Satz spiegelverkehrt gegeneinander: »Der kommt oft am weitesten, der nicht weiss, wohin er geht.« und »Wer sich treiben lässt, ohne Ziel, wird ins Haltlose getrieben.« In dieser Ambivalenz soll Walsers Leben verstanden werden.

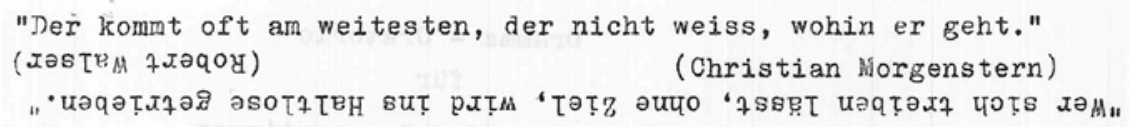

Abb. 4 Wladimir Vogel: Motto zu Flucht am Anfang der Partitur mit irrtümlich Robert Walser zugeschriebenem Kommentar von Paul Müller

Dass das nicht aufgehen kann, zeigt schon die Tatsache, dass beide Texte falsch zugeschrieben wurden: Morgensterns Text ist von diesem selber als von Cromwell stammend bezeichnet worden (vgl. Anm. 28) und die vergebliche Suche der Walser zugeschriebenen Stelle hat schon viel Arbeit gekostet. ${ }^{39}$ Der Autor des Mottos ist der Librettist Paul Müller selbst, wobei der Irrtum beim Abtippen des von Vogel neu zusammengestellten Librettos passiert sein muss: Der im ursprünglichen Libretto mit Spalteneinzug klar gekennzeichnete Unterschied von Müllers Kommentar und Walsers Originaltext (vgl. Abb. 5) wurde beim Abtippen eliminiert. So wurde der ein wenig an eine Sonntagspredigt erinnernde Kommentar von Paul Müller zum zentralen Textteil des Prologs:

38 Geiger: Die Dramma-Oratorien von Wladimir Vogel, S. 177.

39 Schon Friedrich Geiger versuchte den Text vergeblich zu identifizieren (Ebd., S. 167), und er vermutet richtigerweise Paul Müller als Autor. Gelgia Caviezel vom Robert WalserZentrum in Bern war bei der Identifikation ebenfalls erfolglos. Erst das Abhören des Radiofeatures von Paul Müller brachte Klarheit: Dort wird die Stelle nämlich von Müller in seinem eigenen Kommentar gelesen. Später fand ich den Satz dann auch im ursprünglichen Libretto, das Vogel zerschnitt und neu zusammenstellte; vgl. Vogel: Die Flucht [Textbuch]; und Müller: Die Flucht [Erstes Libretto]. 
»Wer von allem frei ist, ist unsäglich einsam; wer sich treiben lässt ohne Ziel, wird ins Haltlose getrieben; wer an allem vorüberzieht, hat keine Heimat und wer nur sich selbst gehören will, wird von niemand geliebt. « ${ }^{40}$

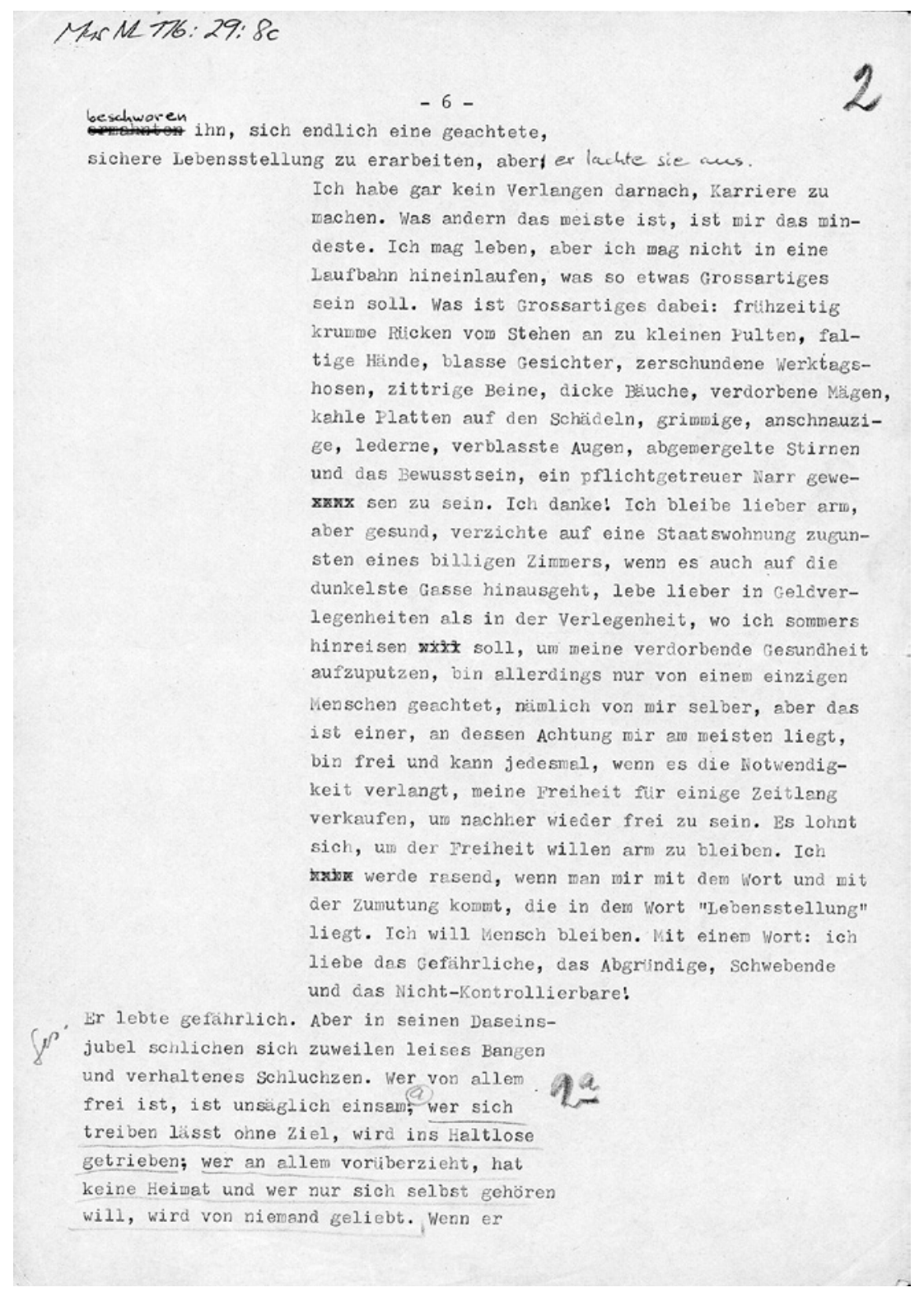

Abb. 5 Paul Müller: Erstes Libretto zu Flucht, S. 6

40 Zit. nach Müller: Die Flucht [Erstes Libretto], S. 6. Der kursiv gesetzte Teil wurde von Vogel - als Walser-Text missverstanden und (trotzdem) leicht modifiziert - ins definitive Libretto übernommen. 


\section{$3 \cdot 7$}

\section{Die Musik zu Flucht}

Schon im Prolog des Oratoriums schafft Vogel eine magisch-impressionistische Stimmung; Sprech- und Singstimmen sind frei übereinandergelegt, was eine Art chaotisches Erwachen suggeriert. Solche musikalisch delikaten und geheimnisvollen Stellen finden sich in diesem Oratorium vor allem dann, wenn in den Sopran- und Altpartien die Frauenfiguren evoziert werden oder in der Tenorpartie aus Jakob von Gunten zitiert wird.

Anzahl und Umfang dieser Stellen, in denen sich die musikalischen Triebkräfte frei entfalten können, sind allerdings zu gering, um dem Oratorium zu einem durchgängigen Spannungsbogen zu verhelfen. Zwar hatte Vogel gerade wegen der Länge des Werkes eine Permutationstabelle erstellt (vgl. Abb. 6), bei der die Zwölftonreihen von Formteil zu Formteil kontinuierlich wechseln. Die Basis bildet eine Allintervallreihe, ein beliebter Spezialfall dodekaphonen Komponierens, in der alle zwölf Intervalle innerhalb einer Oktave je einmal auftreten. Nur ungefähr jede Zehntausendste der möglichen 479001600 (=12!) Reihen weisen diese Charakteristik auf. Allerdings sind das immer noch mögliche 46272 Allintervallreihen. ${ }^{41}$ Die Allintervallreihe tendiert zu einer in der klassischen Zwölftontechnik angestrebten gleichwertigen Verteilung und Gewichtung aller Intervalle. Dies verhindert bei Flucht starke Kontraste, weil aus dem Tonhöhenmaterial keine Differenzen und schon gar keine Hierarchien geschaffen werden können. So sind letztlich auch die Permutationen der Reihe, mit denen Vogel großformale Differenzierung schaffen wollte, im Hören kaum nachvollziehbar. Dazu kommen die reinen Textteile, die oft über längere Abschnitte die Musik unterbrechen, sodass die Tonhöhen-Permutationen die angestrebte formbildende Kraft verlieren.

Aber auch das ist Absicht, denn Vogel wollte in diesem für ihn lebensgeschichtlich zentralen Werk noch eine andere Botschaft vermitteln - und er hat sie mehrfach formuliert: im Programmheft, im Radio, in Vorträgen und sogar in der Partitur selber. Es ist ein Statement gegen die damalige AvantgardeSzene und insbesondere gegen die Darmstädter Schule:

Die Wiederaufwertung des realen und nicht des »verfremdeten« Tones und eine Zurückführung auf die Intervalle, die den Duktus und das Gefüge der musikalischen Struktur bestimmen, charakterisieren die linearen und vertikalen Elemente, wobei Vertrautes und Neuartiges vereinigt und neu erlebt wird. Der Umfang der Instrumente vermeidet dauernde Übertreibungen in Höhen und Tiefen und hält sich im Allgemeinen in normalen Grenzen und in der Ökonomie, um bei charakteristischen Stellen umso wirksamer eingesetzt zu werden.

41 Dank an Viktoria Heu, Institut de Recherche Mathématique Avancée (IRMA) Strasbourg, für die Berechnung. Bei festem Anfangston wären es 3856 mögliche Allintervallreihen. 


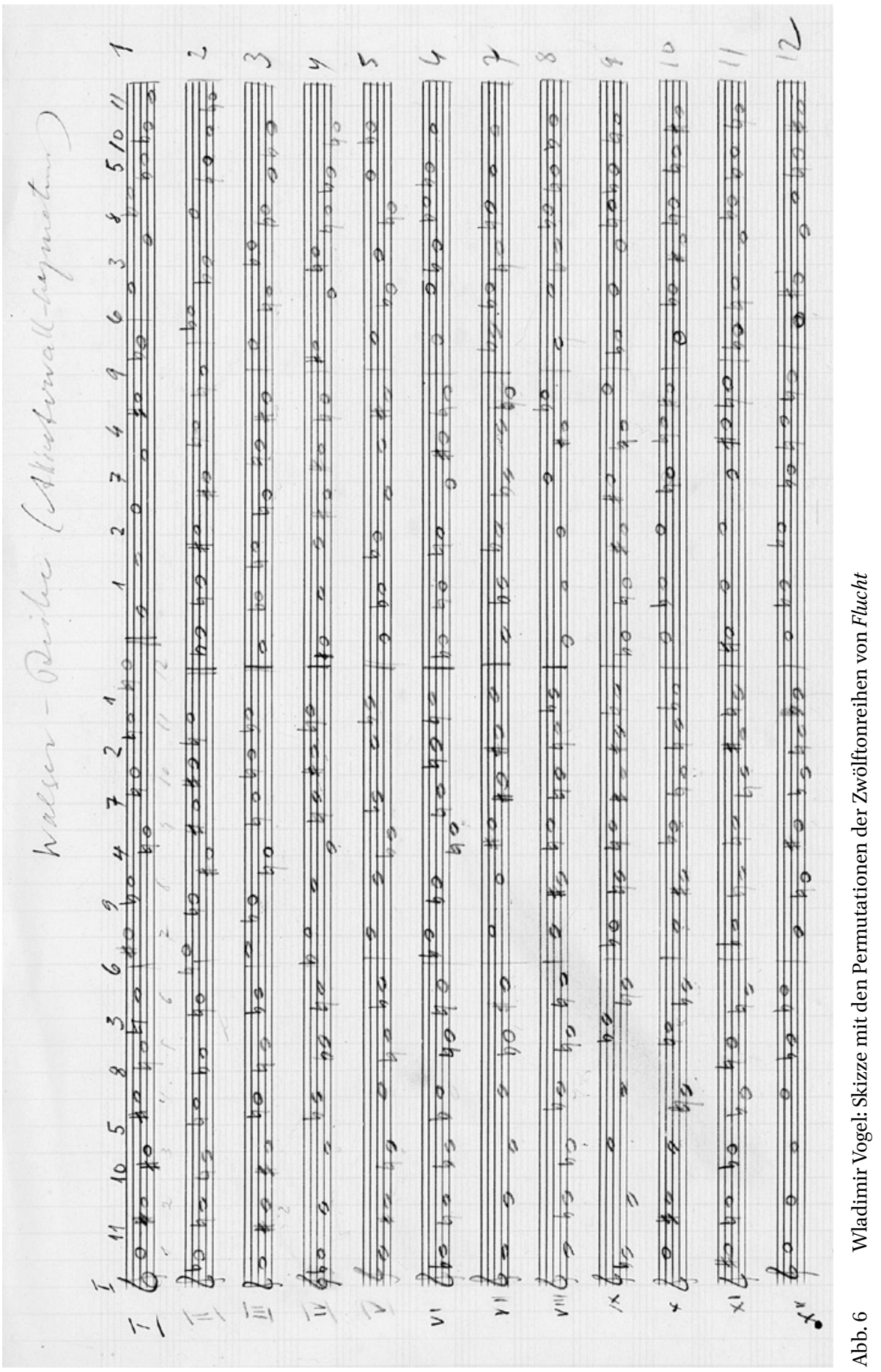


Vermieden wird jede Manieriertheit, aber beibehalten die Merkmale des dodekaphonen Stils.

Ornamentik und Figurationen und grosse dynamische Steigerungen gehören nicht zum Wesen dieser meiner Musik und werden nur dort verwendet, wo es sich aus der Situation der Charakteristik inhaltlich bezogener Vorgänge als notwendig erweist. Verzicht auf jede nur klangliche Ausschmückung, wenn diese nicht vom Inhalt erforderlich oder förderlich erscheint, Beschränkung auf das Wichtigste und Substanzielle des Strukturellen. Bei Singstimmen verwende ich gut intonierbare Intervalle überall dort, wo es strukturell und ausdrucksmässig möglich ist. ${ }^{42}$

Die Spitzen gegen »dauernde Übertreibungen in Höhen und Tiefen«, gegen »Ornamentik und Figurationen« und gegen die »nur klangliche Ausschmückung« richten sich nicht nur gegen die jüngere Generation, darunter auch seinen ehemaligen Schüler Jacques Wildberger, gegen Pierre Boulez, gegen Stockhausen und die elektronische Musik; es ist vor allem auch - und das ist viel fataler - ein Programm gegen Robert Walser selber: Die aus dem Text Vogels herausgefilterten Einsprüche beschreiben ex negativo die eigentlichen Qualitäten von Walsers Schreiben.

Sein konservatives Konzept - das, nebenbei bemerkt, noch einmal belegt, wie wenig Vogel mit Skrjabins Ekstatik zu tun hat - führt dazu, dass es Vogel an musikalischen Mitteln mangelt, ein zweistündiges Werk musikdramaturgisch zu gestalten. So bleibt die Textebene fast immer dominierend. Das abstrakte Grundmaterial der Allintervallreihe kann gegen Walsers starke Sprache und die durchaus pathetisch vorgetragene Biografie nicht ankommen. Zwar gelingt es Vogel quasi gegen die nivellierende dodekaphone Struktur, Kleinmotive im Sinne von musikalischen Signalen oder Erinnerungsmotiven über das Oratorium zu verteilen, aber von der Musik bleiben am stärksten jene Partien haften, bei denen Vogel Assonanzen an Tänze oder Lieder einfügt, also mit >Manierismen< von der abstrakten Sachlichkeit abweicht. Vogels eigentliche Domäne ist das Tragische, und so sind denn die tragischen oder die als tragisch verstandenen Stellen die musikalisch eindrücklichsten: Die Partie zu Walsers Mutter, das Wiegenlied und der Tod des Fräuleins vermögen noch heute beim Anhören der Aufnahme zu berühren. ${ }^{43}$

Oft unbeholfen und sogar ungeschickt ist Vogels Umgang mit allen ironisch gebrochenen Texten Walsers - und das sind bekanntlich viele. Humor war nie

42 Vogel: Die Flucht [Textbuch], S. 2. Ähnlich lautende Aussagen gibt es im Programmheft zur Aufführung am 8. November 1966, im Vorwort der Partitur und in Vogels Manuskript zur Radio-Einführung von Flucht, vgl. [o. A.]: Die Flucht [Programmheft]; Vogel: Die Flucht [Partitur]; ders.: Einführungsvortrag.

Vgl. Vogel: Die Flucht [Aufnahme]. 
eine Qualität seines Komponierens. ${ }^{44}$ Deshalb bleibt ihm die Doppelbödigkeit von Walsers Sprache fremd, ja, er scheint sie zuweilen gar nicht zu verstehen. Dafür erlaubt er sich Text-Wiederholungen, die ihrerseits unfreiwillig komisch wirken. Ein Beispiel für einen solchen >Fehler aus der Chorpartie der Introduktion: Den Satz von Morgenstern »Ob er auch solch einen Gedanken, solch ein neues Wort (wie es Dostojewsky nennt) finden wird, steht dahin «, wird von Vogel mit zusätzlichen Fragmenten von Morgenstern angereichert: »Ob er auch solch einen Gedanken, solch ein neues Wort (wie es Dostojewsky nennt) finden wird, ob er von einem grossen überzeitlichen Gedanken befruchtet wird, einer der stärksten Verlocker zur Freiheit des Geistigen im Individuum wird «; zu allem Überfluss setzt Vogel hier eine lange Pause und erst danach folgt gleich dreimal hintereinander: »steht dahin « ${ }^{45}$ Der Sinn des Satzes ist damit zerstört, denn unter dem »steht dahin « versteht man nicht mehr »muss abgewartet werden«, sondern die einfache Aufforderung: »Steht mal dahin!«

Ein Problem ist auch der Sprechchor. Carlo Piccardi hat aufgezeigt, dass Vogels Sprechchor wesentlich in der Ästhetik der Arbeiterchöre der 1920erJahre verankert ist und Vogel immer wieder eine besondere Kraft gerade aus dieser Tradition schöpfte, was sich vor allem im monumentalen Thyl Claes eindrücklich zeigt, weil hier der Sprechchor als ein musikalisches $>$ Wir $<$ die Geschichten der einzelnen Personen kommentiert. In den Sprechchor-Werken der 195oer-Jahre hat Vogel dieses Wir zunehmend differenziert und parallel zu den wachsenden technischen Möglichkeiten des Kammersprechchors Zürich eine immer raffiniertere und komplexere Polyphonie realisiert. Flucht bildet in Bezug auf die polyphonen Möglichkeiten des Sprechchors, der weitgehend mit musikalischen Laien besetzt war, wohl den Höhepunkt in Vogels Schaffen. Das Problem dabei ist allerdings, dass Walsers Sprache mit den ästhetischen Mitteln eines Sprechchors, mit der Macht und Wirkung gemeinsamen Sprechens und dem Zerlegen in einzelne Wörter, die dann kombinatorisch wiederholt oder zu rhythmischen Ostinati zusammengefügt werden, grundsätzlich nicht beizukommen ist.

44 Vogel hat auch später nicht verstanden, dass andere seinen Humor nicht lustig fanden. In einem der letzten Gespräche, die ich mit ihm führte, zeigte er sich sichtlich enttäuscht darüber, dass Mitglieder des Kammersprechchors Zürich seine Hommage à Alex Sadkowsky auf einen eigenen lustigen Text so gar nicht lustig gefunden hätten.

Vogel: Die Flucht [Partitur], S. 7-10 (Takte 28-35). 


\subsection{Reaktionen und Rezensionen}

Die Uraufführung von Flucht löste ein großes Echo aus; über vierzig Rezensionen in Zeitungen sind dazu erschienen, dazu kommen zahlreiche Radioberichte. Aber gerade weil Vogel seine gemäßigte und konservative Position im Sinne eines ästhetischen Manifests so deutlich erklärt hatte, bot er der Kritik viele Angriffsflächen.

Vor allem das langjährige Erfolgskonzept von Vogel, der Sprechchor, überzeugte bei Flucht viele Kritiker nicht mehr:

Bei der Behandlung des Sprechchores sind gewisse Manierismen nicht vermieden, fast unfreiwillig komisch schon das Händeklatschen zum Namen des »Maikäferkomödie«-Dramatikers und Berner »Bund«-Redaktors Joseph Victor Widmann. ${ }^{46}$

Andere greifen direkt die Musik an, die es nicht geschafft habe, das Werk als Ganzes zusammenzuhalten - auch hier entgegen der von Vogel behaupteten Substanzialität. Rolf Urs Ringger schreibt in der Weltwoche:

Die Deutung liegt nahe: wie Walser das Zeitliche geflohen hat, so flieht Vogels Musik die Zeit. Der Komponist behält recht, dass »eine nur akustische oder rein formal-stilistisch gerichtete Betrachtung völlig abwegig wäre«. Dabei erscheint »Flucht« weniger als Schöpfung eines Musikers, sondern Musik wird als illustrierendes Akzidens zu einem geschlossenen Vorwurf der Sprache. ${ }^{47}$

Und Mario Gerteis meint im Tages-Anzeiger, dass Vogels Konzept, Musik und Text als selbstständige Ebenen zu führen, nicht aufgegangen sei:

Die Musik tritt zwar nicht als Fremdkörper in Erscheinung, aber sie vermag den Text auch nicht wesentlich in tiefere Dimensionen zu führen. Sie bleibt die angemessene Akzentuierung im Dienste eines ergreifenden Lebensbildes. ${ }^{48}$

Sogar Hans Oesch, der erste Biograf Wladimir Vogels und quasi der Mann seines Vertrauens, schreibt in Melos, der damals führenden Zeitschrift für Neue Musik, nachdem er sachlich Vogels Konzept referiert hat:

46 Seelmann-Eggebert: Tonhalle-Gesellschaft Zürich. Wladimir Vogel. Die Flucht. Derselbe Text wurde in der Neuen Zeitschrift für Musik 12/1966 veröffentlicht. Eine gekürzte, aber sonst wortwörtliche Fassung erschien unter dem Namen Carl J. Becher zudem in der Frankfurter Rundschau.

47 Ringger: Die lange Flucht, S. 27.

48 Gerteis: Musikalisches Lebensbild eines Dichters, S. 19. 


\begin{abstract}
Aber: Es ist nicht zu verkennen, dass diese weise Ökonomie auch ihre Nachteile zeitigte. Gemessen an der urtümlichen Kraft eines »Wagadu « oder an der unter die Haut gehenden Direktheit der beiden Teile von »Thyl Claes« ist die Musik des »Walser« über weite Strecken monoton. Wenn dazu kommt, dass (eine Pause miteingerechnet) das Werk zweieinhalb Stunden dauert und auch in der textlichen Vorlage sowie ihrer solistischen wie chorischen Interpretation ohnehin zu epischer (russischer) Breite neigt, muss ernsthaft die Frage gestellt werden, ob das Opus nicht zu groß dimensioniert worden ist. Kommt dazu, dass die Lebensumstände Robert Walsers nun einmal an sich nicht so fesselnd sind wie diejenigen eines Modigliani oder des musikalischen Genies Pergolesi. Gerade, weil es im »Walser« Partien gibt, die von Vogels ungebrochener schöpferischer Kraft zeugen, gerade, weil hier Kompositionserfahrungen zur Synthese gelangt sind, die nur reife Meisterschaft zustande bringt, sind gewisse »Durststrecken « zu bedauern, in denen der Eindruck der Manier seiner selbst aufzukommen droht. Mit bloßen Strichen, wie in einer Routine-Oper ließe sich indessen die »Flucht« nicht straffen, denn die Proportionen stimmen - wie immer bei Vogel. ${ }^{49}$
\end{abstract}

Ein wunderbares Zeitdokument ist die Kritik von »ohr« alias Peter Otto Schneider in der Zeitung Die Tat. Sie zeigt, wie Walser 1966 in der Öffentlichkeit teilweise wahrgenommen und beurteilt wurde. ${ }^{50}$ Die Prosa sei »ridikül« und Walsers Biografie »ein kleines, unwesentliches Leben«:

Liegt nicht der Grundfehler in der Wahl des Stoffes? Das Schicksal von Robert Walser, tragisch und bedauernswert, vermag nicht zu fesseln; es erweckt allenfalls Anteilnahme bei dem, der Walser oder sein Werk näher kennt. Aber Walser[s] dichterischer Beitrag zur deutschen Literatur, heute zwar neu entdeckt, war zu keiner Zeit so, dass er das Interesse an der Persönlichkeit des Dichters erweckt hätte. Die Pubertätsepisode aus dem »Jacob von Gunten«, die den zweiten Teil der »Flucht « ausmacht, wirkt schon als Prosa ridikül. Und das Leben Walsers enthält kein einziges Motiv, das der künstlerischen Darstellung bedürfte, es ist ein kleines, unwesentliches Leben, aus dem die feinen Blüten seiner Dichtungen herauswuchsen. ${ }^{51}$

Auch privat bekommt Vogel kaum positive Rückmeldungen - oder ausweichende, wie die eingangs erwähnten seiner ehemaligen Basler Schüler. Im Falle von Wildberger antwortet Vogel darauf psychologisierend vorwurfsvoll und verrät ein weiteres Mal, wie sehr er die Gestalt von Walser nur durch die sexualmechanische Brille C. G. Jungs wahrzunehmen vermochte:

49 Oesch: Zürich. Musikalisches Porträt des Dichters Robert Walser, S. 427f.

50 Die untergeordnete Wahrnehmung von Robert Walser in der allgemeinen Öffentlichkeit zeigt auch die Tatsache, dass in den Musikkritiken zu Flucht nicht erwähnt wird, dass 1966 auch Walsers zehntem Todesjahr zu gedenken gewesen wäre.

$5^{1} \quad$ Schneider: Wladimir Vogels Walser-Oratorium. Ich danke Heinrich Aerni von der Musikabteilung der Zentralbibliothek Zürich für die Identifizierung des Kürzels »ohr«. 
[E]s freute mich, dass Sie bei der Uraufführung der »Flucht« anwesend waren u. wenn das Werk Ihnen keinen besonderen Eindruck hinterlassen hatte - so hoffe ich, dass Sie die Quintessenz des Stückes begriffen haben u. darum wünsche ich Ihnen dass Sie sich nicht völlig dem »Vorsteher« in Ihnen, ausliefern und das »Fräulein« - ebenfalls in Ihnen selber - pflegen mögen, damit sie nicht in Ihnen erstirbt. $^{52}$

Wildberger geht in seiner Antwort auf diese Insinuationen mit keinem Wort ein und äußert offen die Meinung,

dass Sie in der »Flucht« auf allzuviel von dem verzichtet haben, was Sie bisher zum ausdrucksstarken Komponisten gemacht hat. [...] Ich stosse mich nicht daran, dass Sie sich geradezu polemisch von den Methoden der Jüngeren absetzen; ein gutes Werk braucht nicht die Legitimation des letzten Schreis. [...] Aber: Ich bin nicht überzeugt, dass sich »Ausdruck» so realisieren lässt. ${ }^{53}$

\subsection{Der Dolchstoß}

Der Tat-Kritiker »ohr« macht deutlich, dass auch die Figur von Robert Walser selber ein Grund für den Misserfolg von Flucht gewesen sein könnte. ${ }^{54}$ Der Schriftsteller galt 1966 noch als Geheimtipp, und einige waren der Meinung, dass da ein Erfolgloser und Geisteskranker massiv überschätzt werde.

Jedenfalls war das Kapitel, das der Uraufführung folgte, eine klare Warnung, sich besser nicht mehr musikalisch mit Walser auseinanderzusetzen. Obwohl die Möglichkeit von geplanten Ausstrahlungen des Konzertmitschnitts im deutschen Sprachraum und bereits angebahnte Nachfolge-Aufführungen in ihrer Bedeutung nicht zu unterschätzen waren und anstatt von der in Aussicht stehenden und für damalige Verhältnisse großen Resonanz für Walser $\mathrm{zu}$ profitieren, klagte der die erste posthume Gesamtausgabe betreuende Korrodi-Verlag - auf Initiative des Herausgebers und Walser-Pioniers Jochen Greven - gegen Wladimir Vogel und den Bärenreiter-Verlag. Offenbar hatte man - allerdings vergeblich - schon unmittelbar vor der Uraufführung versucht, diese zu verhindern. ${ }^{55}$ In einer ersten Phase stellten sich die Kläger auf

52 Vogel: Brief vom 14.11.1966.

53 Wildberger: Brief vom 12.12.1966.

54 Vgl. Schneider: Wladimir Vogels Walser-Oratorium, S. 7.

55 Vgl. die Darstellung aus Sicht der Witwe Idmarie Vogel in Geiger: Die Dramma-Oratorien von Wladimir Vogel, S. 186f., die im Folgenden durch Vogels Korrespondenz mit dem Bärenreiter-Verlag ergänzt und bestätigt wird. 
den Standpunkt, Vogel habe keine Rechte für die Vertonung eingeholt. Nachdem sich dieser Vorwurf als nicht haltbar erwies, versteifte sich Greven darauf, Walsers Leben und Schaffen seien unkorrekt dargestellt worden. Gründe dafür fanden sich leicht, und Vogel stellte sich mit seinem Bestreben, keinesfalls Paul Müllers poetisch verhüllte Fassung von Walsers Biografie zu übernehmen, sondern die trockenen, objektiven Lebensdaten zu dokumentieren, selbst in die Schusslinie. Der Versuch, im Oratorium das Ende des Romans Jakob von Gunten mit Walsers Ende kurzzuschließen, und die implizite Suggestion, der Roman sei nach der Berliner Zeit, also in Biel entstanden, wäre in einem rein poetisch-musikalischen Werk als spannende Idee künstlerischer Freiheit aufgefasst worden. Vogel aber spricht im Oratorium immer von Walser, ersetzte also auch in den Partien aus dem Roman Jakob von Gunten den Namen »Jakob« mit »Walser«. Damit suggerierte er eine Dokumentation, die biografischer Wahrheit gerecht wird und sein Werk den Ansprüchen von wissenschaftlicher Faktizität aussetzte. Obwohl Müllers und Vogels Vorgehen, mit Texten und Textausschnitten aus Walsers Werk dessen Leben zu erklären, bei einem Autor, der so ausgedehnt Autobiografisches fingiert, naheliegt und bis heute in der Sekundärliteratur zu Walser vorkommt, konnte Greven eine verfälschende Vereinnahmung von Jakob von Gunten für eine biografische Dokumentation einklagen.

Der Bärenreiter-Verlag überließ die juristische Auseinandersetzung weitgehend Wladimir Vogel. Aus den Unterlagen des Bärenreiter-Verlags geht hervor, dass offenbar der Direktor der schweizerischen Urheberrechtsgesellschaft SUISA, Ulrich Uchtenhagen, Vogel den entscheidenden Schachzug verriet, mit dem sich der Komponist dem juristischen Zugriff entziehen konnte, nämlich den einfachen Trick, den Namen »Walser« im gesamten Werk mit »Jakob « zu ersetzen und sonst keine Note an Partitur und kein Wort am Libretto zu ändern. Das Vorgehen war erfolgreich und Uchtenhagen konnte dem Produzenten von Radio Beromünster im Studio Zürich, Franz Tischhauser, ein knappes Jahr nach der Uraufführung schreiben:

Wir freuen uns Ihnen mitteilen zu können, dass sich Herr Wladimir Vogel mit Herrn Dr. E. Fröhlich, dem Betreuer des Nachlasses von Robert Walser und Vertreter verschiedener literarischer Verläge [sic], auf den Wortlaut einer gemeinsamen Erklärung zu einigen vermochte. Diese Erklärung setzt den Schlussstrich unter den seinerzeit um die Erstsendung des Dramma-Oratorio »Flucht« entstandenen Zwist. Wir bitten Sie, diese Erklärung bei der nächsten Sendung des Werkes am Mikrophon verlesen zu lassen, und erlauben uns, den Wunsch von Herrn Wladimir Vogel um eine baldige zweite Sendung des Werkes nachdrücklich zu unterstützen. Unseres Erachtens sollte die Scharte 
der »Erstsendung mit Vorbehalten« nächstens durch eine »Zweitsendung in Harmonie« ausgewetzt werden. 56

\section{Die beiliegende Erklärung enthielt folgende Vereinbarung:}

Im Dramma-Oratorio »Flucht« von Wladimir Vogel sind verschiedene Ausschnitte aus den autobiographischen Werken des Dichters Robert Walser enthalten. Die Verleger hatten dem Komponisten die Verwendung dieser Werke im Januar 1963 - vor dem Beginn der kompositorischen Arbeiten - erlaubt. Nach der Fertigstellung des Dramma-Oratorio gaben sie der Auffassung Ausdruck, die Auswahl und die Zusammenstellung der Ausschnitte vermittle kein zutreffendes Bild vom Leben des Dichters Robert Walser. Der Betreuer des literarischen Nachlasses schloss sich diesem Standpunkt an. In einer Erklärung, die vor und nach der Erstsendung des Dramma-Oratorios verlesen wurde, brachten Verleger und Nachlass-Betreuer deshalb entsprechende Vorbehalte an.

Wladimir Vogel war es in seinem Werke nicht darum zu tun, das Leben von Robert Walser zu schildern, sondern mit Hilfe von Aussagen dieses Dichters die dem Künstler unserer Zeit drohende Vereinsamung darzustellen.

Komponist, Verleger und Nachlass-Betreuer konnten sich darauf einigen, im Titel und im Text des Werkes noch deutlicher darauf hinzuweisen, dass das Dramma-Oratorio »Flucht« keine Darstellung des Lebenslaufes von Robert Walser bildet. Damit fallen die erhobenen Einwände dahin, so dass das DrammaOratorio »Flucht« in Zukunft ohne Vorbehalte oder Erklärungen aufgeführt oder gesendet werden kann. ${ }^{57}$

Für den für die Klage hauptverantwortlichen Greven muss dies eine schlimme Niederlage gewesen sein und eine enorme Kränkung bedeutet haben, denn mit der bloßen Auswechslung des Namens »Walser« durch »Jakob« wurden auf einen Schlag alle Einwände nichtig und die Dokumentation zu Walsers Leben zur Kunst erklärt. 1992 - ein Vierteljahrhundert nach der Uraufführung und acht Jahre nach Vogels Tod - schäumt Greven noch immer vor Wut, wenn er auf die Uraufführung von Flucht zu sprechen kommt; dabei schildert Greven seinen Standpunkt in solch polemischer, durch das verlorene juristische Verfahren wohl noch gesteigerter Intensität, dass dieser hier in einem umfangreichen Zitat wiedergegeben sei:

Der erste Teil der Aufführung erzählte von einem jungen Dichter, der sich aus der Not gedrückter Verhältnisse ins Unbedingte seiner Berufung aufschwingt, dessen Hoffnungen dann aber an dem Gegensatz zwischen Kunst und Leben,

56 Uchtenhagen: Brief vom o6.og.1967. Zu dieser Zweitsendung, bei der diese Erklärung hätte vorgelesen werden können, kam es nicht.

57 Unsignierte und undatierte Erklärung als Anhang zu Uchtenhagen: Brief vom o6.og.1967. 
Dichtung und Welt zerbrechen. »Aber ließe sich nicht auch so leben? « fragte eine tiefe Männerstimme, und eine helle antwortete: »Walser versuchte es: Er wandte sich den unteren Regionen zu.«

Der Sprechchor malte nun in akzentuiertem Stakkato, mit Brechungen, Wiederholungen und kunstvoll versetzten Überlagerungen aus, wie das zu verstehen war: »Trieb sich in Spelunken und in zweifelhaften Dancings herum, trank und stieß die Gesellschaft vor den Kopf. Die Gesellschaft! - Arbeitete monatelang nichts. Der Verleger stellte die Zahlungen ein, sein Bruder schloß ihn aus; er war am Verkommen. Verzweiflung packte ihn.« Diesem deprimierenden Lagebericht wurde durch gesungene Zitate aus Walsers Prosastück»Bretano (I)« [sic] dann gewissermaßen die schwarzgallige Innensicht gegenübergestellt, und der Chor echote prompt: »Schrecklich, schrecklich ...«

Dieses Beispiel möge genügen, um die Tonlage zu charakterisieren, in der hier das Leben und Trachten eines Beinahe-noch-Zeitgenossen, man könnte sagen, gefeaturet wurde. Übrigens war, folgte man dieser Darstellung, das dichterische Wirken Walsers schon 1913 im wesentlichen beendet. Im zweiten Teil der Aufführung war von einer »Zeit der Genesung « die Rede, aber es wurde dort auch behauptet: »Der Motivkreis wendet sich von der Gegenwart immer mehr in die Erinnerung an die Frühzeit des Dichters zurück«, und wie um das zu belegen, erklang in Deklamation und Gesang eine Art Digest-Fassung des Romans Jakob von Gunten, der bekanntlich in Wirklichkeit schon 1908 in Berlin entstanden ist. Der dritte Teil endlich war auch schon ein Epilog: Der Dichter, der den Namen Robert Walser trägt, hat das Gefühl, sich in einer Wüste aufzuhalten, die Seele verdorrt ihm, Schuldgefühle erdrücken ihn, er verstummt und geht in die Anstalt. Am Ende der Tod im Schnee, und ein Baß singt die Walser-Worte: »Ach, daß man den Tod im Tode fühlen und genießen dürfte«.

Daß die dem Anstaltsaufenthalt vorausgehenden acht (oder, zählt man die Waldau-Zeit hinzu, sogar zwölfeinhalb) Berner Jahre seine fruchtbarste Zeit als Autor waren, daß die Hälfte seines Werks erst in dieser Periode entstand, daß der Mensch Robert Walser in Bern nicht nur Krisen, sondern auch ausgesprochen glückliche Phasen, Erfahrungen des Sichverjüngtfühlens, leidenschaftliche Liebesempfindungen und Schübe inspiriertester Kreativität erlebte - wen kümmerte es. Das Klischee des tragischen, von Apoll geschlagenen, von der Gesellschaft verstoßenen Dichters, ein bißchen poète maudit, ein bißchen Hölderlin, tat, mit dem nur gerüchtweise bekannten Namen Robert Walsers und einer pseudodokumentarischen Spiegelung seines Lebensschicksals verknüpft, seine Wirkung: Es ließ das bürgerliche Kunstpublikum dankbar erschauern. Über die Trivialität der Zurichtung trug die Pathetik und Exotik der musikalischen und sprecherischen Gestaltung hinweg. ${ }^{58}$

58 Greven: Figur am Rande, S. 106f. Vogel befindet sich in >guter Gesellschaft, denn Greven verfährt ähnlich kritisch mit Gert Hofmann, E. Y. Meyer, Jürg Amann und - etwas milder Urs Widmer; vgl. ebd., S. 106-116. 
Das Zitat zeigt, dass Greven noch 1992 unfähig war, Paul Müllers Sicht auf Walser im Kontext der Jahre 1962/63 zu betrachten, anstatt sie lächerlich zu machen. ${ }^{59}$

\subsection{Das Ende}

Für Vogel war die Intervention von Jochen Greven verheerend. Weitere Aufführungen und auch die Radio-Aufnahme der Uraufführung waren während eines Jahres gesperrt. Schon vor der Erstausstrahlung am 11. November 1966 musste eine Bemerkung verlesen werden, die suggerierte, dass die folgende Darbietung nicht der Wahrheit entspreche. Nach der erwähnten Einigung 1967 musste die Konzertaufnahme auf komplizierte Weise überarbeitet werden, um die Passagen mit dem Namen »Walser« durch neu von Ellen Widmann eingesprochene Aufnahmen zu ersetzen, in denen der Name »Walser« mit »Jakob « ersetzt wurde. Dabei musste auch die Akustik der Tonhalle nachgestellt werden, was technisch erstaunlich gut gelöst wurde.

Die Einigung mit dem Kossodo-Verlag stieß bei Bärenreiter auf wenig Begeisterung. Man ärgerte sich darüber, dass nun wegen der textlichen Änderungen im Libretto 1 ooo Klavierauszüge eingestampft werden sollten. ${ }^{60}$ Zudem wollte Bärenreiter endlich Erfolge sehen, wobei sich Vogel und der den Verlag vertretende Wolfgang Timaeus die Verantwortung gegenseitig zuschoben. ${ }^{61}$ Vogel schlug Aufführungen in einem Theaterraum vor; er reagierte dabei auf die Kritik vor allem von Hans Oesch, dass Flucht musikalisch nicht genügend trage. Aufgrund der ambivalenten Aufnahme des Dramma-Oratorio sah sich Vogel sogar veranlasst, im Nachhinein das Werk in der Schweizerischen Musikzeitung ausführlich zu verteidigen. Der Name von Robert Walser taucht in diesem wenig kohärenten und in verschiedenste Richtungen ausschlagenden Text gar nicht mehr auf. In Bezug auf den

59 Obwohl die meisten der von Greven inkriminierten Textstellen des Librettos auf Müller zurückgehen, hält er den Herisauer Redaktor nicht der Erwähnung wert. Auch in seinem ausführlichen Rückblick auf die Walser-Rezeption, in dem er die »eifersüchtige Inbeschlagnahme der Person und des Werkes« (ebd., S. 133) durch Seelig erwähnt, taucht Müllers Name nicht auf (vgl. ebd., S. 133-140). Zur Kritik von Grevens Argumentation vgl Geiger: Die Dramma-Oratorien von Wladimir Vogel, S. 179f.

6o Dies wird in einem Brief von Hans Möller (Bärenreiter-Verlag) an Vogel vorwurfsvoll formuliert; vgl. Möller: Brief vom 23.08.1967.

61 Ich danke Patrick Kast vom Bärenreiter-Verlag für die freundliche Kopie des Dossiers zu Vogel im Archiv des Bärenreiter-Verlags, das für die vorliegende Publikation zum ersten Mal gesichtet wurde. 
Aufführungsraum kommt Vogel auch hier zum Schluss, dass eine Aufführung in einem Theaterraum >richtiger wirken würde als in einem Konzertsaal, sonst aber beharrt er auf seiner Position und lässt keine der vorgebrachten Kritiken gelten. ${ }^{62}$

Am 7. Januar 1969 - mehr als zwei Jahre nach der Uraufführung - schreibt Vogel dem Verlag einen begeisterten Brief, in dem er mitteilt, dass nun endlich die Rechte für die Radioaufnahme geklärt seien, das Tonband in vorzüglicher Überarbeitung vorliege und man die Flucht für 3 ooo.- Schweizer Franken (als Entschädigung für die Solisten und die Tonhalle-Musiker) übernehmen könne. ${ }^{63}$

$\mathrm{Zu}$ diesem Zeitpunkt hatte man im Bärenreiter-Verlag allerdings längst beschlossen, die Zusammenarbeit mit Vogel abzubrechen. Nach dem Misserfolg von Flucht wollte man kein Risiko mehr eingehen und hatte zum nächsten Werk, das Vogel einsandte, Hörformen für Orchester, ein externes Gutachten bestellt. Diese von »dlM « unterzeichnete Beurteilung - Patrick Kast vom Bärenreiter-Verlag vermutet, dass es sich dabei um den Musiktheoretiker und Komponisten Diether de la Motte handelt ${ }^{64}$ - fasst in aller Schärfe zusammen, wie sehr sich Vogels musikalischer Spätstil aus der Sicht der jüngeren Generation überlebt hat:

Hörformen - kein lockender Titel: Das klingt zu sehr nach Unterrichtsstunde, nicht nach Konzert.

Die Musik hat einen höchst verwunderlichen Standort. Motorische Flächen [...] zeigen an "gemäßigte Moderne mit Einbeziehung des Vitalen und Musikantischen «. Dem aber widerspricht alles Übrige. Es handelt sich um aneinandergereihte, in sich statische »Tapetenmuster-Flächen«. Keine Entwicklungen, keine starken motivisch-thematischen Persönlichkeiten, obwohl die Musik ständig dergleichen erwarten lässt! Was sich über den »Tapeten« tut [...] ist als Kantilene einfach kümmerlich, zu ausgetrocknet. Es fehlt jede Sinngebung für die motorische Arbeitsamkeit, sie führt zu nichts. Die Musik ist geschlechtlos, ausgetrocknet. Für »Fortner« hat sie zu wenig konstruktivInteressantes, für »K. A. Hartmann« viel zu wenig Saft und Kraft.

Im Viva-Bereich kann man damit nicht landen und fürs Sinfoniekonzert ists zu einfallsschwach. Ich bin entschieden für NEIN.65

62 Vgl. Vogel: Nachwort zur Uraufführung der »Flucht«; nachgedr. in ders.: Schriften und Aufzeichnungen, S. 56-61.

63 Vgl. Vogel: Brief vom 17.01.1969.

64 Das bestätigte mir auch de la Mottes Schüler Martin Skamletz: De la Motte habe noch in Wien Korrekturen jeweils mit »dlM « unterschrieben.

65 De la Motte: Wladimir Vogel, »Hörformen« für gr. Orchester 1967. Am Rande dieser Notiz findet sich ein handschriftlicher Kommentar »also nein! «, datiert mit 15. Oktober 1968. Die hier besprochenen Hörformen für Orchester (VWV 38) wurden dann im Selbstverlag 
So bekommt Vogel auf seinen hoffnungsvollen Brief vom 7. Januar 1969 eine Woche später den Bescheid, dass der Verlag die Hörformen $»$ vor allem [aus] rein wirtschaftliche[n] Überlegungen « nicht edieren werde. ${ }^{66}$ Und am 19. Mai 1969 endet der Kontakt zum Bärenreiter-Verlag mit einer trockenen Mitteilung:

Wir haben wiederholt den deutschen Rundfunkanstalten das Band FLUCHT von Radio Studio Zürich angeboten. Leider war die Resonanz völlig negativ. Im Augenblick sehe ich mich außer Stande, in dieser Angelegenheit jetzt noch einmal vorstellig zu werden. ${ }^{67}$

Damit blieb es bis heute bei einer einzigen Gesamtübertragung im Radio und einer einzigen Aufführung von Flucht. Nach diesem schon fast monumentalen Misslingen von Flucht beschränkte sich Vogel auf eine nationale und vor allem regionale Karriere. Die meisten folgenden Werke brachte er im Eigenverlag heraus. Er fand wie früher Interpretinnen und Interpreten, die sein Werk regelmäßig aufführten, und Walter Labhart übernahm eine wichtige Rolle in der Publikation seiner Schriften und der Zusammenstellung eines zuverlässigen Werk-Verzeichnisses.

Trotz seiner Bekanntheit im Zürcher Musikleben musste Vogel seinen 85. Geburtstag beim Zürcher Stadtpräsidenten in Erinnerung rufen und vorschlagen, dass zu diesem Anlass ein Werk von ihm aufgeführt werden könnte.

Ganz am Ende seines Lebens löste sich schließlich der private Konflikt mit Aline Valangin, der im Uraufführungsjahr von Flucht 1966 zum Abbruch der Beziehung geführt hatte: Es kam wieder zu einem sporadischen Brief-Kontakt und Vogels letzte Komposition sind Lieder über Gedichte von Valangin. Im letzten Brief an sie fügt er in einem Postscriptum an: »Falls Du Musils $>$ Der Mann ohne Eigenschaft< [sic] und Proust's >A la recherche du temps perdu< nicht brauchst, würde ich mich gerne damit befassen. ${ }^{68}$

Im tizianischen Alter wollte sich Vogel also noch mit Proust und Musil auseinandersetzen. Die Lieder enden mit Valangins Worten: Höre fern den Dreiklang; solcher Fang ist selten; er mag gelten.« ${ }^{69}$

herausgegeben und am 11. Mai 1971 von keinem Geringeren als Hans Zender als Dirigent mit dem Tonhalle-Orchester in Zürich uraufgeführt.

66 Timaeus: Brief vom 13.01.1969.

67 Timaeus: Brief vom 19.05.1969.

68 Vogel: Brief vom 12.04.1984.

69 Vogel: Rückkehr und Folge. 


\subsection{Vorschlag für eine Wiederaufführung}

Für eine mögliche Wiederaufführung von Flucht hat Vogel selbst die entscheidenden Hinweise gegeben, nämlich verstärkt die Mittel des Theaters zu verwenden. Allerdings war Vogel in seiner Zeit viel zu einseitig auf episches Theater fixiert und damit auf den Verzicht des >Spielens< der Figuren. In den letzten Jahrzehnten hat sich im postdramatischen und im experimentellen Musiktheater viel verändert und die einfache Dichotomie von Dramatik und Epik hat sich überholt. Da gäbe es heute zahlreiche Möglichkeiten, neue Qualitäten der Flucht zu zeigen, Zeitbedingtes und Pathos zu brechen, zu relativieren und im Spiel sogar zu kommentieren. Denkbar wäre sogar der Einbezug von Dokumenten aus den zahlreichen Materialien im Umfeld der Uraufführung.

In der Partitur schlägt Vogel selber eine Variante für die Aufführung auf der Theaterbühne vor. Zwar sollen Sprechchor und Sänger starr auf der Bühne stehen, aber die Schauspieler möchte er kostümieren und schminken. Dazu sollen statt eines Bühnenbildes im Hintergrund Projektionen eingeblendet werden, »aber nur angedeutet ohne den Zuschauer zu stark und dauernd abzulenken.« Auch hier wieder schwingt Vogels Vorurteil mit, das Visuelle könnte von Musik und Wort ablenken. In der Introduktion sollen »Bilder von Robert Walser und Christian Morgenstern« projiziert werden, im ersten Teil

Bildprojektionen der Stadt Biel und Umgebung aus der Zeit Ende des vorigen Jahrhunderts (evtl. nach älteren Gravuren) und nach Ortsangaben im Text. Bilder des Vaters, der Mutter und der Geschwister Walser's. Robert Walser als Kind, dann als Jüngling. Bilder der wechselreichen Arbeitsstätten des Dichters, der Erzählung folgend. ${ }^{70}$

Im langen Jakob von Gunten-Teil sah Vogel keine Projektionen vor, erst der dritte Teil und der Epilog sollten wieder Bilder enthalten:

Bilder aus dem ersten Weltkrieg. Dann wieder Stadt Biel, evtl. Hotel zum »Blauen Kreuz«. Bild der Schwester Hedwig. Herisau und Umgebung. Heil- und Pflegeanstalt Herisau. Letztes Bild Robert Walser's. Wald und Kuppe der Wachtlenegg. ${ }^{71}$

70 Vogel: Die Flucht [Partitur], S. IV.

71 Ebd. Walser lebte während seiner Bieler Zeit von 1913 bis 1920 im Hotel Blaues Kreuz am Unteren Quai. Beim Namen der Schwester irrt Vogel: Hedwig ist eine Figur in Walsers Roman Geschwister Tanner, deren Vorbild dessen ältere Schwester Lisa ist. Mit »Wald und Kuppe der Wachtlenegg « meint er Walsers Sterbeort, die Wachtenegg oberhalb Herisau. 
Für seine Zeit, die von Lichtbild-Vorträgen dominiert war, denkt Vogel durchaus innovativ; und er ahnt, dass es zusätzlicher Mittel bedarf, nur fürchtet er sich vor der Maschinerie Theater und hält auch mit einer gewissen Sturheit an seinem Konzept des Dramma-Oratorio fest. Man muss nur an die Produktionen von Ruedi Häusermann, an Mischa Käsers Nettchen oder an Georges Aperghis' Zeugen erinnern (vgl. Kap. 7 und 8), um bewusst zu machen, wie erfolgversprechend Flucht heute grundsätzlich neu konzipiert werden könnte.

Auch der legendäre Kammersprechchor Zürich, der sich 2010 nach 59 Jahren wegen Mitgliederschwunds und fehlendem neuem Repertoire auflöste, könnte heute durch entsprechend ausgebildete Performerinnen und Performer aus dem Bereich Théâtre musical mit einem klein besetzten Ensemble professioneller Musiker und Sprecherinnen ersetzt werden. Schwächen wie die stereotypen Frauenfiguren - Mutter, Hure und Heilige - könnten mit Mitteln des Figurentheaters dargestellt und zugleich in ihrer Maskenhaftigkeit reflektiert werden.

Das würde einen grundsätzlichen Perspektivenwechsel erlauben: Flucht wäre dann nicht einfach das gescheiterte Lebenswerk, in das sich Zeitbedingtes in Form von moralisierendem Pathos oder ästhetischen Abgrenzungen gegenüber der damaligen Avantgarde eingeschrieben hat, sondern ließe sich in seiner ganzen Komplexität neu wahrnehmen. Vieles, was Vogel an seinem 70. Geburtstag so wichtig war, ist heute bedeutungslos geworden: Die Gattung des Dramma-Oratorio ist vergessen, die Diskussion über die richtige Verwendung der Dodekaphonie ist ebenso Geschichte wie der Streit um die richtige oder falsche Walser-Interpretation.

Der Versuch einer Neuproduktion von Flucht unter den Bedingungen des postdramatischen und des experimentellen Musiktheaters und unter Einbezug der >Ornamentik « und der >Übertreibungen «, die Vogel in seiner konservativen Polemik ausschloss, müsste gewagt werden. 